\section{New Chemiluminescent Reactions Involving Coordination Compounds}

ARND VOGLER* ${ }^{\dagger}$, LYLA EL-SAYED, RICHARD G. JONES**, JIM NAMNATH and ARTHUR W. ADAMSON ${ }^{\dagger}$

Department of Chemistry, University of Southern California, Los Angeles, Calif. 90007, U.S.A.

Received September 4, 1980

Most chemiluminescent reactions in the literature are biological or at least organic in nature [1-4]. Rather few cases are known in which it is a coordination compound that is produced in an emitting state. The best known such instance is that of the chemiluminescent reduction of $\mathrm{Ru}(\mathrm{bipyr})_{3}^{3+}$ (bipyr denoting $2,2^{\prime}$-bipyridine) by hydroxide ion [5], hydrazine [5], and alkaline borohydride [6], this last reductant giving the most brilliant light. Spectral analysis shows the emission to be from the same excited state of $\mathrm{Ru}\left(\right.$ bipyr) ${ }_{3}^{2+}$ as that produced by photoexcitation. The emission may also be produced by the reaction of electrogenerated $\mathrm{Ru}\left(\right.$ bipyr) ${ }_{3}^{+}$and Ru(bipyr) (3) $_{3}^{3^{+}}$[7] .

We report here the following chemiluminescent reactions, which we believe to be new:

$$
\begin{aligned}
& \mathrm{Ru}\left(\text { bipyr) } 3_{3}^{3+} \stackrel{0.1 \mathrm{~N} \mathrm{H}_{2} \mathrm{SO}_{4}}{\longrightarrow}\right. \\
& {\left[\mathrm{Ru}(\text { bipyr })_{3}^{2+}\right] *+\left(\mathrm{O}_{2}, \mathrm{H}_{2} \mathrm{O}_{2}\right)} \\
& \mathrm{Cr}(\text { bipyr })_{3}^{2+}+\mathrm{Ce}(\mathrm{IV}) \stackrel{0.4-1 \mathrm{~N} \mathrm{H}_{2} \mathrm{SO}_{4}}{\longrightarrow} \\
& {\left[\mathrm{Cr}(\text { bipyr })_{3}^{3^{+}}\right]^{*}+\mathrm{Ce}(\mathrm{III})} \\
& \mathrm{Cr}(\text { bipyr })_{3}^{2+}+\mathrm{Ru}(\text { bipyr })_{3}^{3+} \rightarrow \\
& {\left[\mathrm{Cr}(\text { bipyr })_{3}^{3+}\right]^{*}+\mathrm{Ru}(\text { bipyr })_{3}^{2+}} \\
& \left.\mathrm{Rh}(\text { bipyr })_{2}^{+}+\mathrm{Br}_{2}(\mathrm{aq}) \rightarrow[\text { cis-Rh(bipyr })_{2} \mathrm{Br}_{2}^{+}\right]^{*} \\
& \left.\operatorname{Ir}(\text { phen })_{2}^{+}+\mathrm{Cl}_{2}(\mathrm{aq}) \rightarrow[\text { cis-Ir(phen })_{2} \mathrm{Cl}_{2}^{+}\right]^{*} \\
& (\mathrm{OC})_{5} \operatorname{Re}-\operatorname{Re}(\mathrm{CO})_{3}(\mathrm{phen})+\mathrm{Cl}_{2} \stackrel{\mathrm{DMF}}{\longrightarrow} \\
& \mathrm{Re}(\mathrm{CO})_{5} \mathrm{Cl}+\left[\operatorname{Re}(\mathrm{CO})_{3}(\text { phen }) \mathrm{Cl}\right] \text { * }
\end{aligned}
$$

where phen and DMF denote $o$-phenanthroline and dimethylformamide, respectively, and the starred

\footnotetext{
†uthors to whom correspondence should be addressed.

*Permanent address: Department of Chemistry, University of Regensburg, Regensburg, F.R.G.

**Permanent address: Department of Chemistry, University of Kent, Canterbury, U.K.
}

species indicate our assignment of the emitting product.

Our interest in chemiluminescence stemmed from the earlier observation with $\mathrm{Ru}(\mathrm{bipyr})_{3}^{3^{+}}$borohydride reduction [6], and also from some studies on the chemiluminescent autoxidation of unsaturated fatty acids [8]. This last was in the category of 'weak' chemiluminescence, that is, the photon yields were in the range of $10^{-12}$ to $10^{-6}$, requiring a photon counter for detection of the light emission. The two experiences combined to suggest that weak chemiluminescence might be a more general phenomenon than usually suspected, and one not necessarily involving oxygen as a reactant. Reaction (1) was observed during the course of the work reported in Ref. 8; the other reactions have been found from current searching. In this, we used the criteria that (a) the reaction produce a product known to show photoexcited emission, and (b) the reaction be strongly exoergic and not likely to be mechanistically complicated.

The measurements were made with equipment similar in performance to that described in Ref. 8 , but equipped with a slide holder so that filters could be interposed between the sample and the red-sensitive photomultiplier (Dumont KM 2433). The emissions were in the range of $10^{5}$ to $10^{7}$ photons $\mathrm{sec}^{-1}$, and, from the amount of reaction typically occurring, the photon yields were in the range of $10^{-9}$ to $10^{-10}$.

\section{Solvent Reduction of $R u(\text { bipyr })_{3}^{3+}$}

$\mathrm{Ru}$ (bipyr) 3 $_{3}^{3^{+}}$was prepared in situ by $\mathrm{PbO}_{2}$ oxidation, and the suspension then filtered (see Ref. 6). The analytical or overall ground-state reaction corresponding to (1) has been studied over a range of $\mathrm{pH}$ [9], and a tentative mechanism was proposed, involving intermediates in which water or hydroxide has added to one of the rings. While the stoichiometry, that is, the nature of the solvent oxidation products, is not established for the solvent reduction of $\mathrm{Ru}$ (bipyr) $3_{3}^{3^{+}}$in acidic solutions, we find that the complex is not significantly changed in ligation, the final product solution having the absorption spectrum of $\mathrm{Ru}$ (bipyr) $)_{3}^{3^{+}}$. Moreover, the decrease in chemiluminescence intensity with time paralleled, within experimental error, the disappearance of $\mathrm{Ru}\left(\mathrm{bipyr} \mathbf{3}^{\mathbf{3}^{+}}\right.$. It appears, therefore, that the step producing [ $\mathrm{Ru}-$ (bipyr) $\left.)_{3}^{2+}\right]^{*}$ occurs subsequent to the rate determining step for the analytical reaction. Since [Ru(bipyr) $\left.3_{3}^{2+}\right]^{*}$ lies about $2.2 \mathrm{~V}$ above the ground state, or, alternatively, the standard reduction potential for the $\mathrm{Ru}(\text { bipyr })_{3}^{3^{+}}\left[\mathrm{Ru}(\text { bipyr })_{3}^{2+}\right]^{*}$ couple is about $1 \mathrm{~V}$ vs. NHE [10], the intermediate involved in the chemiluminescent step must be a fairly high energy 
one. Temperature dependence studies on the chemiluminescence yield should be of interest.

\section{Oxidations of $\mathrm{Cr}$ (bipyr $)_{3}^{2+}$}

Cr(bipyr) $)_{3}^{2+}$ was prepared by a Jones reduction of acidic chromic chloride solution, followed by addition of bipyridine [11]. The qualitative observations of chemiluminescence were made by adding an aliquot of oxidizing solution, through a syringe, to a deaerated suspension of $\left[\mathrm{Cr}(\mathrm{bipyr})_{3}\right]\left(\mathrm{NO}_{3}\right)_{2}$ in the sample vial that was viewed by the photomultiplier. For more quantitative studies, the oxidant aliquot was added to a deaerated solution of $\mathrm{Cr}$ (bipyr) ${ }_{3}^{2+}$.

In the case of reaction (3), both products show photuexcited emission, of course, so either could have been the source of the chemiluminescence. The two photoexcited emissions are at quite different wavelengths, however. That for $\left[\mathrm{Cr}(\text { bipyr })_{3}^{3+}\right]^{*}$ centers at $727 \mathrm{~nm}[12,13]$, while that for [Ru(bipyr) $\left.{ }_{3}^{2+}\right]^{*}$ is in the $575-625 \mathrm{~nm}$ region [14]. By use of appropriate interference filters, it was determined that the emission was indeed from the less energetic excited state, $\left[\mathrm{Cr}(\text { bipyr })_{3}^{3^{*}}\right]^{*}$. The chemiluminescence spectrum was also determined in the case of reaction (2) by using a succession of cut-off filters. The derived spectrum, shown in Fig. 1, agrees well with the published one for $\left[\mathrm{Cr}(\text { bipyr })_{3}^{3+}\right]^{*}$ produced by photoexcitation [15].

When the Ce(IV) oxidant was added to a solution of $\mathrm{Cr}$ (bipyr) ${ }_{3}^{2+}$, the emission occurred as an instantaneous spike (on the 2-3 second resolution time scale of the quantum counter), followed by a weaker residual emission which decayed with about a one minute half-life. It is the emission spectrum of the spike that conforms to that for $\left[\mathrm{Cr}(\text { bipyr })_{3}^{3^{+}}\right]^{*}$; that for the slow-decaying emission was centered at about $750 \mathrm{~nm}$, and apparently was due to some different reaction. In the acidic solutions that necessarily were used (to avoid hydrolysis of the Ce(IV)), it is likely that oxidation products included species such as $\mathrm{Cr}(\text { bipyr })_{2}\left(\mathrm{H}_{2} \mathrm{O}\right)_{2}^{3^{+}}$, the emission spectrum for which has not been reported. This aspect is under further investigation. The analytical reaction behavior paralleled that of the chemiluminescence. There was an instantaneous spectrophotometric change, followed by a slower one with about a minute half-life. The product absorption spectrum, as suspected, indicated the presence of aquated forms.

The standard oxidation potential for theCr(bipyr) $)_{3}^{2+} / \mathrm{Cr}$ (bipyr) $)_{3}^{3+}$ couple is $0.26 \mathrm{~V}$ vs. NHE [10], and those for the $\mathrm{Ce}(\mathrm{III}) / \mathrm{Ce}$ (IV) and $\mathrm{Ru}$ (bipyr) ${ }_{3}^{2+} / \mathrm{Ru}\left(\right.$ bipyr) ${ }_{3}^{3+}$ couples are about $-1.7 \mathrm{~V}$ [16] an $-1.26 \mathrm{~V}$ (see Refs. 9, 10), respectively. We can estimate the free energy difference between ground and excited state $\mathrm{Cr}$ (bipyr) ${ }_{3}^{3+}$ as about $1.7 \mathrm{~V}$, from the short wave-length edge of the emission spectrum and thus obtain $-1.4 \mathrm{~V}$ for the $\mathrm{Cr}(\text { bipyr })_{3}^{2+} /$

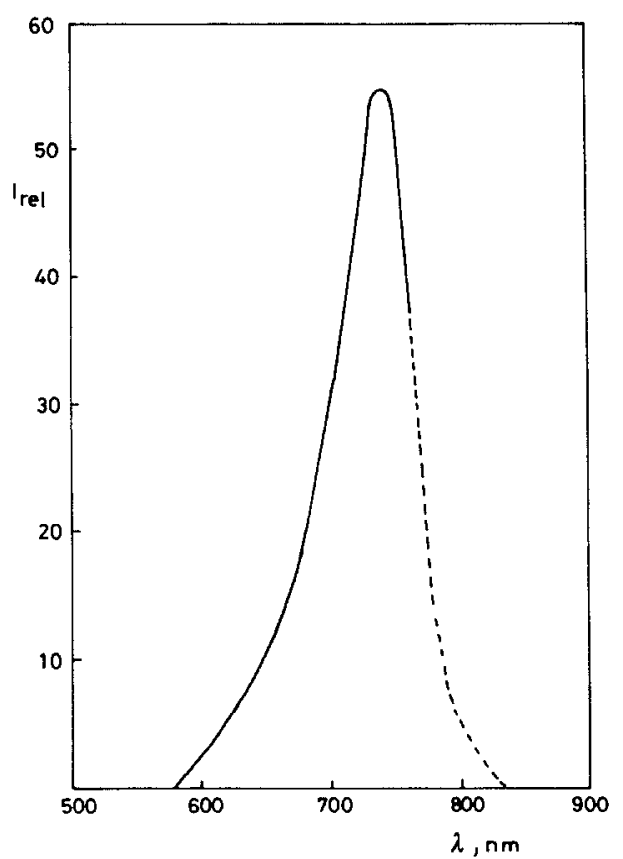

Fig. 1. Chemiluminescence spectrum for reaction (2).

$\left[\mathrm{Cr}(\text { bipyr })_{3}^{3^{+}}\right]^{*}$ couple. The standard potentials for reactions (2) and (3) can thus be estimated to be 0.3 $\mathrm{V}$ and $-0.1 \mathrm{~V}$, respectively. The two reactions thus appear to be allowed in terms of overall energetics, unlike the situation for reaction (1).

It should be noted that the emission yield on photoexcitation of $\mathrm{Cr}$ (bipyr) $3_{3}^{3^{+}}$is low, around $10^{-4}$ $[15,17]$, presumably mainly because of competing deactivation paths. The actual yield of $\left[\mathrm{Cr}(\text { bipyr })_{3}^{3^{+}}\right]$* in reactions (2) and (3) may thus be $10^{4}$ larger than the photon yield, or of the order of $10^{-5}$ to $10^{-6}$.

\section{Oxidation of $R h\left(\right.$ bipyr $h_{2}^{+}$}

$\mathrm{Rh}$ (bipyr) ${ }_{2}^{+}$was prepared by reduction of $\mathrm{Rh}$ (bipyr) ${ }_{2} \mathrm{Br}_{2}^{+}$with borohydride (see Refs. 18, 19). The full stoichiometry of reaction (4) is under investigation; the main product appears to be the cis isomer of $\mathrm{Rh}$ (bipyr) ${ }_{2} \mathrm{Br}_{2}^{+}$, although some trans isomer and aquo products may also be present. Both isomers show low temperature photoexcited emission [20, 21], the short wave-length edge of the emission spectrum for the cis isomer placing [Rh(bipyr $\left.)_{2} \mathrm{Br}_{2}^{+}\right]^{*}$ at about $2.1 \mathrm{~V}$ above the ground state. The standard potential for reaction (4) is not known. However, the reduction of $R$ h(III) bipyridine complexes to $R h$ (bipyr) ${ }_{2}^{+}$requires a strong reducing agent, and it therefore seems likely that in reaction (4) there is sufficient energy to permit population to the emitting state. Again, temperature dependence studies of the chemiluminescence yield may be informative.

\section{Oxidation of Ir $(\text { phen })_{2}^{+}$}

Cis- $\operatorname{Ir}(\text { phen })_{2} \mathrm{Cl}_{2}^{+}$was prepared by a literature procedure [22], and $\operatorname{Ir}(\text { phen })_{2}^{+}$was then obtained in 
situ by reduction of a solution of the former complex by borohydride. As in the case of reaction (4), the products of reaction (5) may include some trans$\operatorname{Ir}(\text { phen })_{2} \mathrm{Cl}_{2}^{+}$and aquo species, but the principal ground state product appears to be cis-Ir(phen) ${ }_{2}$ $\mathrm{Cl}_{2}^{+}$. Photoexciled emission has been reported for this last species (see Refs. 23, 24); it is solvent and temperature dependent, and there has been some experimental problem with emitting impurities. The candidate emission centers at about $500 \mathrm{~nm}$, corresponding to an excitation energy of $2.5 \mathrm{~V}$ for $\left[\operatorname{Ir}(\text { phen })_{2} \mathrm{Cl}_{2}^{+}\right]^{*}$. This is greater than for $\left[\mathrm{Rh}(\text { bipyr })_{2}\right.$. $\left.\mathrm{Br}_{2}^{+}\right]^{*}$, but reaction (5) may still be energetically allowed because of the stronger oxidant used. The chemiluminescence for this system was also observed using the triboluminescence equipment of J. I. Zink.

\section{Reaction of $(\mathrm{OC})_{5} \mathrm{Re}-\mathrm{Re}(\mathrm{CO})_{3}$ (phen) with Chlorine}

The starting complex (see ref. 25) was prepared by boiling $\operatorname{Re}_{2}(\mathrm{CO})_{10}$ with $o$-phenanthroline in undecane solution and purified by recrystallization from chloroform. The complex is not soluble in water, and the oxidation was conducted in DMF solution. The principal products of reaction (6), $\operatorname{Re}(\mathrm{CO})_{5} \mathrm{Cl}$ and $\operatorname{Re}(\mathrm{CO})_{3}($ phen $) \mathrm{Cl}$, may have been contaminated by reaction by-products, but we tentatively assign the emission to $\operatorname{Re}(\mathrm{CO})_{3}$ (phen) $\mathrm{Cl}$, which is known to show photoexcited emission, centered at $580 \mathrm{~nm}\left(25^{\circ} \mathrm{C}\right.$, EPA solvent $)[26,27]$. This system showed the strongest chemiluminescence of those reported here, by about an order of magnitude. Interestingly, electrogenerated chemiluminescence has been reported for $f a c-\operatorname{Re}(\mathrm{CO})_{3}$ (phen)Cl [28] .

Investigations are in progress to establish reaction stoichiometries and the correctness of the emitting state assignments, where these are now in doubt. A possible complication to be noted is that where related products are present, excitation energy transfer can alter the nature of the emitting species from that produced by the major reaction path (see Ref. 29, for example). It may be accidental that all six systems reported here involve aromatic nitrogen chelates. Condition (a) in our screening of candidate reactions necessarily led us to emphasize such complexes because of the prevelance of literature reports of photoexcited emission. Saturated ammine type complexes of $\mathrm{Cr}(\mathrm{III}), \mathrm{Rh}$ (III), and Ir(III) can show detectable emission, as do various cyano complexes; their chemiluminescent product may be possible.

We present this preliminary report as encouraging evidence that chemiluminescent reactions involving coordination compounds are likely to be widespread, so that a large new field of investigation is indicated. The study of chemiluminescent reactions and their kinetics may come to be an important adjunct to that of ground state kinetics.

\section{Acknowledgement}

The investigations were supported by the U.S. National Science Foundation.

\section{References}

1 A. W. Adamson, 'Concepts of Inorganic Photochemistry', A. W. Adamson and P. F. Fleischauer, Eds., Wiley (1975).

2 F. McCapra, Accts. Chem. Res., 9, 201 (1976).

3 N. J. Turro, P. Lechtken, N. E. Schore, G. Schuster, H. C. Steinmetzer and A. Yekta, Accts. Chem. Res., 7, 97 (1974).

4 G. B. Schuster, Accts. Chem. Res., 12, 366 (1979).

5 F. E. Lyttle and D. M. Hercules, Photochem. Photobiol., $13,123(1971)$.

6 H. D. Gafney and A. W. Adamson, J. Chem. Ed., 52, 480 (1975).

7 N. E. Tokel-Takvoryan, R. E. Hemingway and A. J. Bard, J. Am. Chem. Soc., 95, 6582 (1973).

8 V. Slawson and A. W. Adamson, Lipids, 11, 471 (1976).

9 C. Creutz and N. Sutin, Proc. Nat. Acad. Sci. U.S.A., 72, 2858 (1975).

10 See B. Brunschwig and N. Sutin, J. Am. Chem. Soc., 100, 7568 (1978).

11 See (a) B. Baker and B. D. Mehta, Inorg. Chem., 4, 848 (1965) and (b) G. B. Porter and J. Van Houten, Inorg. Chem., 18, 2053 (1979).

12 N. A. P. Kane-Maguire, J. Conway and C. H. Langford, Chem. Comm., 801 (1974).

13 K. DeArmond and L. S. Forster, Spectrochim. Acta, 19, 1403 (1963).

14 See J. N. Demas and A. W. Adamson, J. Am. Chem. Soc., $93,1800(1971)$.

15 M. S. Henry and M. Z. Hoffman, 'Inorganic and Organometallic Photochemistry', M. S. Wrighton, Ed., Adv. in Chem., 168, 91 (1978).

16 Handbook of Chemistry and Physics, 57th ed., R. C. Weast, Ed., Chemical Rubber Co., Cleveland (1977).

17 Unpublished work in this Laboratory.

18 R. D. Gillard, J. A. Osborn and G. Wilkinson, J. Chem. Soc., 1951 (1965).

19 B. Martin, W. R. McWhinnie and G. M. Waind, J. Inorg. Nucl. Chem., 23, 207 (1961).

20 D. A. W. Carstens and G. A. Crosby, J. Mol. Spectroscopy, 34, 113 (1970).

21 J. N. Demas and G. A. Crosby, J. Am. Chem. Soc, 92, $7262(1970)$.

22 J. A. Broomhead and W. Grumley, Inorg. Chem., 10, 2002 (1971).

23 R. Ballarđini, G. Varani, L. Moggi and V. Balzani, J. Am. Chem. Soc., 99, 6881 (1977).

24 R. J. Watts and D. Missimer, J. Am. Chem. Soc., 100, 5350 (1978).

25 D. L. Morse and M. S. Wrighton, J. Am. Chem. Soc., 98, 3931 (1976).

26 M. S. Wrighton and D. L. Morse, J. Am. Chem. Soc., 96, 998 (1974).

27 S. M. Fredericks, J. C. Luong and M. S. Wrighton, J. Am. Chem. Soc., 101, 7415 (1979).

28 J. C. Luong, L. Nadjo and M. S. Wrighton, J. Am. Chem. Soc., 100, 5790 (1978).

29 N. A. P. Kane-Maguire, C. G. Toney, B. Swiger, A. W. Adamson and R. E. Wright, Inorg. Chim. Acta, 22, L11 (1977). 